\title{
Fatty Acid Profile of Eggs of Semi-Heavy Layers Fed Feeds containing Linseed Oil
}

Author(s)
Souza JG',2
Costa FGP ${ }^{3}$
Queiroga RCRE
Silva JHV5
Schuler ARP6
Goulart CC 1,7
1 Ph.D. Student of Animal Science Post-
Graduation Program/ UFPB. Areia, PB, Brazil.
2 Part of the thesis
3 Professor of the Dept. of Animal Science/
UFPB. Areia, PB, Brazil.
4 Professor of the Dept of Nutrition/ UFPB
5 Professor of the Dept of Agriculture/CFT/
UFPB. Bananeiras, PB, Brazil.
6 Professor of the Dept. of Chemical
Engineering/UFPE. Recife, PE, Brazil.
7 Professor of the Dept of Animal Science /
UVA. Sobral, CE, Brazil.

Mail Address

Janete Gouveia de Souza

Rua Fernando dos Santos Leal, 841/02

Bairro Cidade Universitária

58.397-000. Areia, PB, Brazil.

E-mail: jnobre5@hotmail.com

Egg, enrichment, fatty acids.

\section{ABSTRACT}

The incorporation of polyunsaturated fatty acids in chicken eggs by adding oils to the diets has been extensively studied. This experiment aimed at evaluating possible changes in the fatty acid profile of the eggs of layers fed diets supplemented with linseed and soybean oils. The experiment was performed using 19229 week-old laying hens, distributed in a completely randomized design, into six treatments with four replicates of eight birds each. Treatments consisted of a control diet (no vegetable oil) and diets including $2 \%$ of vegetable oil. Linseed oil replaced $0,25,50,75$, and $100 \%$ soybean oil in the diets, corresponding to $0.0,0.5,1.0,1.5$, and $2.0 \%$ of linseed oil in the diet. A pool of two egg yolks from each treatment was submitted to lipid extraction and fatty acid methylation, and subsequent gas chromatography (GC) analysis to detect seven fatty acids. Saturated (myristic and palmitic) fatty acids concentration was affected by lipid dietary source, with the lowest concentration in birds were fed feeds containing linseed oil. Polyunsaturated fatty acids (PUFA) concentration in the eggs was influenced by different levels of linseed oil inclusion. Linoleic acid egg content increased when linseed oil was used on diet as compared to the control diet. Linseed oil was considered an excellent source of linolenic acid incorporation in the eggs.

\section{INTRODUCTION}

The egg is considered a functional food (Stadelman, 1999), as it is a source of protein, vitamins, and lipids, such as phospholipids and polyunsaturated fatty acids (Meluzzi et al., 2000; Anton et al., 2006). In the production of eggs rich in n-3 fatty acids, there is an increasing interest in maximizing the use of feedstuffs containing these nutrients because there is a correlation between their levels in feeds and in the yolk (Leeson et al., 1998). The egg is naturally poor in linolenic acid, and does not contain eicosapentoenoic (EPA) and docosahexaenoic (DHA) fatty acids.

Omega-3 polyunsaturated fatty acids (PUFA $n-3$ ) have been extensively studied in human health, as well as $n-6$ fatty acids, which are considered essential in human diets. Linolenic acid (LNA, 18:3, n-3) can be metabolically converted into docosahexaenoic (DHA, 22:6, n-3) and eicosapentaenoic (EPA, 20:5, n-3) fatty acids, but the enzymes involved in this process are common to the elongation and desaturation of linolenic acid (LNA), and therefore the competition with n- 6 fatty acids reduces the amount of converted LNA (Gómez, 2003).

One of the main dietary sources of long-chain $n-3$ polyunsaturated fatty acids is fish, which is rich in EPA and DHA. Oilseed oils, particularly linseed oil, are rich in linolenic acid, a precursor of those fatty acids (Calder, 1998). 
Souza JG, Costa FGP, Queiroga RCRE, Silva JHV, Schuler ARP, Goulart CC
When hens were fed diets containing fish oil (Van Elswik et al, 1992; Marshall et al., 1994) and linolenic acid (Ahn et al., 1995), eggs presented higher linolenic acid, EPA, and DHA levels, which in turn decreased arachidonic acid egg content (Gao and Charter, 2000).

Some ingredients may be included in layers feeds to produce eggs with higher content of polyunsaturated fatty acids. Mandarino (1992) observed that soybean oil has $49 \%$ to $59 \%$ linoleic acid and $2 \%$ to $8.5 \%$ linolenic acid. When that author compared soybean oil with coconut oil, sunflower oil, corn oil, olive oil, and palm oil, he verified that the higher content of PUFA in soybean oil is more favorable to egg production.

According to Van Elswyk (1997), the enrichment of eggs with PUFA can be obtained by supplementing layer feeds with marine-fish oils or oilseed oils, such as linseed, sunflower, and canola oils, as they promote the incorporation of these acids into the yolk. Containing approximately $7 \%$ of $n-3$ fatty acids (linolenic acid) in its total fatty acid content, soybean oil can also be used to change egg lipid profile. In the 1960s and 1970s, Sell et al. (1968) and Sim et al. (1973) showed that the inclusion of soybean oil in layer feeds changed the fatty acid composition of the yolk. Some researchers (Baucells et al., 2000; Grobas et al., 2001; Gómez, 2003; Mazalli et al., 2004a,b) demonstrated the possibility of changing the fatty acid profile of the lipid fraction of the egg by reducing the dietary concentration of some fatty acids (trans fatty acids, lauric acid, and other short-chain saturated fatty acids) and increasing the inclusion of eicosapentaenoic acid (EPA, C20:5 n-3) docosahexaenoic acid (DHA, C22:6 $n-3)$, designated as long-chain fatty acids because their chemical structure contains more than 18 carbon atoms. However, the maintenance of an adequate ratio between $n-6$ and $n-3$ fatty acids is necessary.

The enrichment of layer feeds with marine-fish oils, algae, and oilseeds, such as linseed, promotes the rapid incorporation of $\omega-3$ fatty acids into the egg yolk (Van Elswyk, 1997). In addition to its high content in álinolenic acid (50-55\%), the interest in linseed use is related to the presence of dietary fiber, lignans, and phenolic compounds, which may reduce risk factors for cardiovascular diseases and cancer (Chen et al., 1994).

Taking these aspects into consideration, this study aimed at evaluating fatty acid profile and n-3 LNA incorporation in eggs of layers fed a diet supplemented with linseed oil.
Fatty Acid Profile of Eggs of Semi-Heavy Layers Fed Feeds containing Linseed Oil

\section{MATERIAL AND METHODS}

The experiment was carried out at the poultry sector of the Department of Animal Science of the Federal University of Paraíba, Areia, PB, Brazil, during 140 days divided into five 28-d periods. Average temperature was $24.7^{\circ} \mathrm{C}$, with average maximum and minimum temperatures of $28.5^{\circ} \mathrm{C}$ and $20.9^{\circ} \mathrm{C}$, respectively.

A total number of 192 Bovans Goldline commercial layers, with 29 weeks of age at the beginning of the trial, was distributed in a completely randomized experimental design into 6 treatments, with four replicates of eight birds each. treatments consisted of a control diet (no vegetable oil inclusion) and five diets with $2 \%$ vegetable oil inclusion $(2.800 \mathrm{kcal} \mathrm{ME} / \mathrm{kg}$ and $18 \%$ CP - Table 1) with replacement of $0,25,50,75$, and $100 \%$ soybean oil by linseed oil, resulting in 0.0 , $0.5,1.0,1.5$, and $2.0 \%$ linseed oil in the diet. Feed were formulated to supply bird requirements, according to Rostagno et al. (2005).

Birds were housed in galvanized wire cages, placed $1,0 \mathrm{~m}$ above the floor, located in a poultry house with clay-tiled roof, and open sides. Four birds were housed in each cage $\left(525 \mathrm{~cm}^{2} / \mathrm{bird}\right)$. Trough feeders and nipple drinkers were used. Birds received water and feed ad libitum during the entire experimental period.

In order to determine total lipid content and fatty acid composition, eggs were collected at the end of each experimental period, identified, and stored under refrigeration until analyses were performed. In the laboratory, eggs were broken and intact yolks were separated. Yolk of two eggs per replicate per treatment were individually weighed and homogenized. This yolk pool was placed in glass flasks. Yolk lipid content was determined using the technique of Folch et al. (1957).

Lipids were extracted by weighing two grams of raw yolk, and adding $100 \mathrm{~mL}$ of chloroform-methanol solution (2:1). This mixture was agitated for two minutes, and then filtered using a separation funnel, and $20 \mathrm{~mL} \mathrm{KCl}$ at $0.72 \%$ were added. After phase separation, $17.5 \mathrm{~mL} \mathrm{KCl} 0.72 \%$ were added, and the mixture was agitated again, for further phase separation. The chloroform extract was transferred to a $100 \mathrm{~mL}$ volumetric flask, completing the volume with chloroform.

Methylation was carried out according to the method of Hartman and Lago (1973). One $\mathrm{mL}$ of the chloroform extract lipid solution was transferred to tubes with polished lids, and chloroform was evaporated using gas nitrogen. 
Souza JG, Costa FGP, Queiroga RCRE, Silva JHV, Schuler ARP, Goulart CC
Fatty Acid Profile of Eggs of Semi-Heavy Layers Fed Feeds containing Linseed Oil

\begin{tabular}{|c|c|c|c|c|c|c|}
\hline \multirow[b]{2}{*}{ Ingredients } & \multicolumn{6}{|c|}{ Linseed oil levels (\%) } \\
\hline & Control & 0.0 & 0.5 & 1.0 & 1.5 & 2.0 \\
\hline Corn & 62.700 & 56.850 & 57.018 & 57.185 & 57.353 & 57.520 \\
\hline Soybean meal & 22.501 & 23.857 & 23.637 & 23.417 & 23.196 & 22.976 \\
\hline Soybean oil & 0.000 & 2.000 & 1.500 & 1.000 & 0.500 & 0.000 \\
\hline Linseed oil & 0.000 & 0.000 & 0.500 & 1.000 & 1.500 & 2.000 \\
\hline Corn gluten & 3.616 & 3.447 & 3.585 & 3.724 & 3.862 & 4.000 \\
\hline Limestone & 8.690 & 8.676 & 8.677 & 8.679 & 8.680 & 8.681 \\
\hline Dicalcium phosphate & 1.494 & 1.506 & 1.507 & 1.507 & 1.508 & 1.508 \\
\hline Dl-Methionine & 0.147 & 0.155 & 0.154 & 0.153 & 0.151 & 0.150 \\
\hline Lysine HCL & 0.027 & 0.000 & 0.005 & 0.011 & 0.016 & 0.021 \\
\hline Cholin chloride (70\%) & 0.070 & 0.070 & 0.070 & 0.070 & 0.070 & 0.070 \\
\hline Mineral premix ${ }^{1}$ & 0.050 & 0.050 & 0.050 & 0.050 & 0.050 & 0.050 \\
\hline Vitamin premix ${ }^{2}$ & 0.025 & 0.025 & 0.025 & 0.025 & 0.025 & 0.025 \\
\hline Antioxidant ${ }^{3}$ & 0.010 & 0.010 & 0.010 & 0.010 & 0.010 & 0.010 \\
\hline Salt & 0.492 & 0.494 & 0.494 & 0.495 & 0.495 & 0.495 \\
\hline Inert material ${ }^{4}$ & 0.178 & 2.860 & 2.769 & 2.677 & 2.586 & 2.494 \\
\hline Total & 100.000 & 100.000 & 100.000 & 100.000 & 100.000 & 100.000 \\
\hline \multicolumn{7}{|l|}{ Calculated analysis } \\
\hline Metabolizable energy (kcal/Kg) & 2800 & 2800 & 2800 & 2800 & 2800 & 2800 \\
\hline Crude protein (\%) & 18.000 & 18.000 & 18.000 & 18.000 & 18.000 & 18.000 \\
\hline Ether extract (\%) & 3.590 & 5.756 & 5.760 & 5.765 & 5.769 & 5.774 \\
\hline Calcium (\%) & 3.800 & 3.800 & 3.800 & 3.800 & 3.800 & 3.800 \\
\hline Av. phosphorus (\%) & 0.375 & 0.375 & 0.375 & 0.375 & 0.375 & 0.375 \\
\hline Lysine (\%) & 0.750 & 0.750 & 0.750 & 0.750 & 0.750 & 0.750 \\
\hline Methionine (\%) & 0.426 & 0.430 & 0.430 & 0.430 & 0.429 & 0.429 \\
\hline Methionine + cystine (\%) & 0.683 & 0.683 & 0.683 & 0.683 & 0.683 & 0.683 \\
\hline Threonine (\%) & 0.595 & 0.597 & 0.597 & 0.597 & 0.596 & 0.596 \\
\hline Sodium (\%) & 0.230 & 0.230 & 0.230 & 0.230 & 0.230 & 0.230 \\
\hline Linolenic acid (\%) & 1.416 & 2.391 & 2.205 & 2.019 & 1.832 & 1.646 \\
\hline
\end{tabular}

1 - Composition/kg: manganese - 160g, iron -100g, zinc -100g, copper -20g, cobalt -2g, iodine- 2g, excipient q.s.p. - 1000 g. 2 - Composition/kg: vit. A 12.000 .000 U.I., vit $D_{3} 3.600 .000$ U.I., vit. E 3.500 U.I., vit $B_{1} 2.500$ mg, vit $B_{2} 8.000$ mg, vit $B_{6} 5.000$ mg, pantothenic acid 12.000 mg, biotin 200 mg, vit. K 3.000 mg, folic acid $1.500 \mathrm{mg}$, nicotinic aci 40.000 mg, vit. $B_{12} 20.000$ mg, selenium 150 mg, excipient q.s.p. - 1000 g. 3 - Ethoxiquin

- 10 g. 4 - Washed sand.

Saponification was conducted by adding $2 \mathrm{~mL}$ of sodium hydroxide methanol solution at $0.5 \mathrm{~N}$, and heating in water bath for five minutes.

Fatty acids were esterified by adding to the lipid extract $6 \mathrm{~mL}$ of esterification agent (methanol + ammonium chloride + sulfuric acid), heating the tubes in boiling water for three minutes. After cooling, addition of $5 \mathrm{~mL}$ cold water, and agitation, methylic esters were extracted in three successive portions of $2.0 \mathrm{~mL}$ hexane, after which the upper phase was transferred to another tube, where $5.0 \mathrm{~mL}$ of saturated sodium carbonate solution $\left(\mathrm{NaHCO}_{3}\right)$ was added. The upper phase was then transferred to a test tube for solvent evaporation, and $1.0 \mathrm{~mL}$ hexane was added to the methylic residues before chromatographic analysis.

Fatty acid separation, detection, and identification were carried out in a gas chromatographer model HP 5890 series II, equipped with a flame ionization detector, slipt/splitless injector, and fused silicon capillary column HP INNOWAX, 30m length x $0.25 \mu \mathrm{m}$ internal diameter $\times 0.25 \mathrm{~mm}$ liquid phase film. Operation parameters were fixed at temperatures of $230{ }^{\circ} \mathrm{C}$ for the injector, and $250{ }^{\circ} \mathrm{C}$ for the detector; initial temperature of $60{ }^{\circ} \mathrm{C}$ for the column with $8{ }^{\circ} \mathrm{C} / \mathrm{min}$ increase, and $250^{\circ} \mathrm{C}$ final temperature; $100: 1$ split ratio, and helium as dragging gas with $1 \mathrm{~mL} / \mathrm{min}$ column flow; detector gases: hydrogen, with $16.7 \mathrm{~mL} / \mathrm{min}$ flow, and synthetic air, with $310 \mathrm{~mL} / \mathrm{min}$ flow.

A 1.0 $\mathrm{LL}$ aliquot of the sterified extract was injected in the chromatographer. Retention time and fatty acid percentage data were obtained using the software Peaksimple (SRI Instruments - USA).

Fatty acids were identified by comparing retention times $\left(t_{r}\right)$ of the methyl esters of the fatty acids in the samples with authentic fatty acid samples (Merck, USA).

Data were submitted to analysis of variance, using the software SAEG (1999). The test of Dunnet at 5\% probability was used to compare the treatment with no oil inclusion (control) with the other treatments, after which analysis of regression of the treatments with graded dietary inclusions of linseed oil was performed. Each treatment consisted of three replicates of six eggs each, summing up 18 eggs per treatment. 
Souza JG, Costa FGP, Queiroga RCRE, Silva JHV, Schuler ARP, Goulart CC

\section{RESULTS AND DISCUSSION}

Table 2 shows the fatty acid composition of the egg yolk of layers fed graded levels of linseed oil, as analyzed by gas chromatography (GC). The presence of seven fatty acids was determined.

Saturated fatty acid content (myristic and palmitic fatty acids) was influenced $(p<0.05)$ by fatty acid source, with lower concentrations in the eggs of layers fed diets containing only linseed oil. The highest concentration of myristic acid was detected in the eggs of the layers fed the control diet as compared to the other treatments, and this concentration decreased as linseed oil inclusion increased ( $p<0.05)$. For each $0.5 \%$ replacement of soybean oil by linseed oil, a $0.045 \%$ reduction was estimated $\left(\hat{Y}=0.7391-0.0908 x, r^{2}=\right.$ $0.76)$. The lowest palimitic acid concentration was found in the eggs of hens fed the highest linseed oil level.

Stearic acid egg content was significantly different when the control treatment was compared with the combination $1.5 \%$ linseed oil $+0.5 \%$ soybean oil. In general, the concentration of this acid in eggs is very stable and little influenced by diets with high unsaturated fatty acid levels. According to Li-Chan et al. (1995) and Simopoulos (2000), saturated fatty acids comprise 30 to $38 \%$ of total fatty acid content in the yolk, independent of the lipid type added to layer diets.

The lowest oleic acid levels were observed at dietary inclusions of 0.5 and $1.5 \%$ linseed oil. According to Cherian \& Sim (1991), dietary omega-6 and omega-3 polyunsaturated fatty acids are more effective in reducing monounsaturated than saturated fatty acids in eggs due the inhibition of the activity of the enzyme $\mathrm{D}^{9}$ desaturase in the production of oleic acid.

The concentration of polyunsaturated fatty acids (PUFA) in the egg was influenced $(p<0.05)$ by the
Fatty Acid Profile of Eggs of Semi-Heavy Layers Fed Feeds containing Linseed Oil

different linseed oil inclusion levels in the diet. Linoleic acid (LA) egg content increased when linseed oil was supplemented, as compared to the control treatment (no oil addition). The results of the present experiment indicate that egg fatty acid profile can be changed according to dietary lipid composition. Mazzali et al. (2004a) compared different lipid sources in layer diets and showed that yolk lipid composition is influenced by fatty acid dietary sources, resulting in eggs with different fatty acid profile, particularly as to n-3 polyunsaturated fatty acids. Filardi et al. (2005), evaluating the influence of different fat sources (cotton seed, soybeans, sunflower, and canola oils) in the diet on lipid profile of the yolk of second-cycle layers, verified that the most significant changes, such as lower saturated fatty acid content, higher levels of linolenic and docosahexanoic (DHA), and lower linoleic acid levels, were caused by canola oil addition; however, there was no promote enrichment of the eggs with polyunsaturated fatty acid.

Sunflower oil, which contains high linoleic (LA) levels, and linseed oil, which is rich in linolenic acid (LNA), increase egg content of these acids. This was observed in the studies of Scheideler \& Froning (1996) and VanElswyk (1997), with dietary inclusions of 5 and $10 \%$ whole linseed, resulting in eggs with 144 and $293 \mathrm{mg}$ LNA, respectively. Mazzali et al. (2004 b) verified that the inclusion of $9 \%$ whole linseed in the diet resulted in eggs with $3.67 \%$ LNA.

Due to the competition between n-3 and n- 6 for the same enzymes for their biosynthesis (Watkins, 1991; Aymond, 1995), high LNA (C18:3n-3) level limits the synthesis of arachidonic acid (C20:4n-6) from LA (C18:22-6). LNA competes with LA for the enzyme $D^{6}$ desaturase. Mazzali et al. (2004b) observed that the inclusion of linseed oil, with high linolenic acid (LNA) content, decreased the synthesis of arachidonic acid

Table 2 - Concentration (\%) of saturated (SFA), monounsaturated (MUFA), and polyunsaturated (PUFA) fatty acids in the eggs produced by layers fed different linseed oil levels.

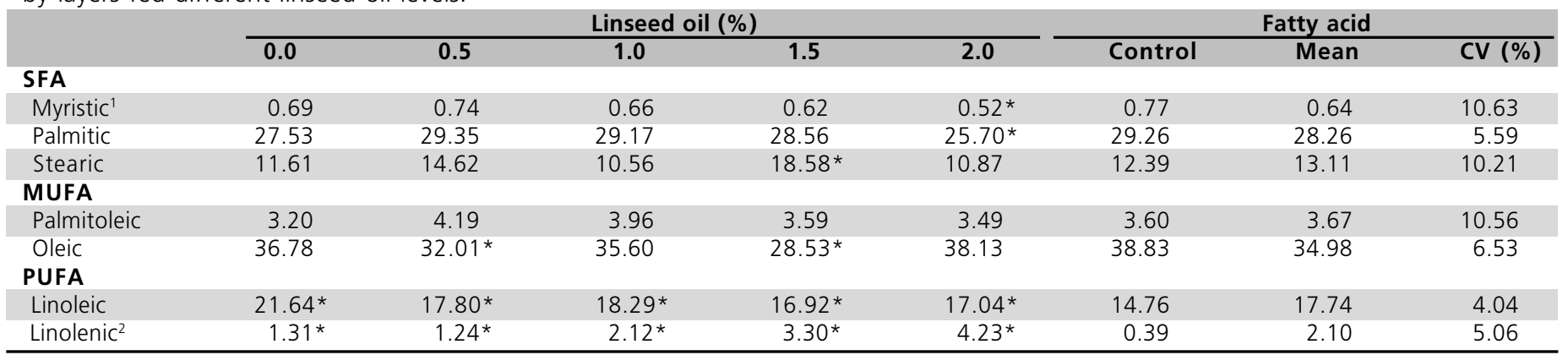

* : Means significantly different from the control treatment, Dunnet's test at 5\% probability. 1 - Linear effect at $5 \%$ de probability. 2 - Linear effect at $1 \%$ de probability. 
Souza JG, Costa FGP, Queiroga RCRE, Silva JHV, Schuler ARP, Goulart CC
Fatty Acid Profile of Eggs of Semi-Heavy Layers Fed Feeds containing Linseed Oil from linoleic acid (LA). In the present study, this was not observed, as arachidonic acid was not detected under the conditions to which samples were analyzed. On the other hand, Milinsk et al. (2003) verified that arachidonic acid egg content is not influenced by dietary polyunsaturated fatty acid levels, and Cobos et al. (1995) did not find an increase in arachidonic acid content in the eggs of layers fed diets rich in soybean, linseed, or sunflower oil.

Linolenic acid (LNA) egg content increased $(p<0.01)$ as a function of dietary linseed oil in the present experiment. For each $0.5 \%$ of replacement of soybean oil by linseed oil, there was a $0.8 \%$ increase in linolenic content in the yolk $\left(Y=0.8599+1.5804 x, r^{2}=0.92\right)$.

Studies have been carried out to increase $\omega$-3 polyunsaturated fatty acid content in eggs by manipulating layer diets with the use of marine oils and/or oilseed oils (Gómez, 2003). Caston and Leeson (1990) studied the influence of diets containing 0, 10, 20 , and $30 \%$ linseed on egg yolk composition. Those authors found higher LNA yolk contents when linseed was included in the diet, and the dietary level of $20 \%$ was the most effective. When $10 \%$ linseed was added to the diet, there was a 10-fold increased LNA egg content as compared to the diet with no linseed. Lewis et al. (2000) included 7\% linseed oil in a commercial control diet and observed that $\omega-3$ PUFA content increased $1.2 \%$ to $7.8 \%$ in the egg yolk, and that LNA increased 30 times.

Table 3 presents the total concentration of saturated (SFA), unsaturated (UFA), monounsaturated (MUFA), and polyunsaturated (PUFA) fatty acids, unsaturated to saturated ratio (UFA:SFA), polyunsaturated to saturated ratio (PUFA:SFA), linolenic to linoleic (LNA:LA), and omega 6 to omega 3 ratio $(n-6: n-3)$ found in the present study.

The total concentration of saturated fatty acids was significantly influenced by the treatments with 1.5 and $2 \%$ replacement of soybean oil by linseed oil as compared to the control treatment. The treatment with $2 \%$ linseed oil promoted the highest saturated fatty acid reduction, influencing unsaturated fatty acid content. The ingestion of these acids instead of saturated fatty acids is nutritionally healthier.

Treatments influenced $(p<0.05)$ total PUFA (LA and LNA) egg content, and those that included linseed oil presented higher values as compared to the control. This may be explained by the high PUFA content in linseed oil. These results are consistent with the findings of Milinsk et al. (2003), who observed an increase in PUFA egg percentage when evaluating four diets containing n-3 fatty acids.

All experimental diets containing oil resulted in eggs with higher polyunsaturated fatty acid concentrations as compared to the control diet, which did not contain oil. Nutritional quality can be assessed by the LNA:LA and $n-6: n 3$ ratios. Linseed oil contains high LNA levels, therefore increasing the content of this fatty acid in the egg yolk, promoting changes in those ratios. In the present study, unsaturated to saturated fatty acid ratio was significantly different as compared to the control treatment. Shafey et al. (1992) observed that the supplementation of diets with soybean oil increased the unsaturated (oleic and linoleic) to saturated (palmitic and stearic) fatty acid ratio of the egg yolk. This higher ratio improves the nutritional quality of eggs for human consumption. There was a linear effect of linseed oil dietary inclusion on LNA:LA and $w-6: w-3$ ratios $(p<0.01)$. For each $0.5 \%$ replacement of soybean oil by linseed oil, a 0.05 increase and a 3.92 reduction, respectively, were estimated $\left(y=0.0335+0.103 x, r^{2}\right.$ $\left.=0.96 ; y=18.081-7.8471 x, r^{2}=0.95\right)$. Simopoulos (2000) suggested that the optimal dietary w-6: w-3 fatty acid ratio is between 4 and 10 . In the present experiment, this ratio was significantly influenced by oil dietary inclusion as compared to the control treatment, and it improved as a function of the replacement of soybean oil by linseed oil.

\begin{tabular}{|c|c|c|c|c|c|c|c|c|}
\hline & \multicolumn{5}{|c|}{ Linseed oil (\%) } & \multicolumn{3}{|c|}{ Fatty acid } \\
\hline & 0.0 & 0.5 & 1.0 & 1.5 & 2.0 & Control & Mean & CV (\%) \\
\hline Saturated (SFA) & 39.60 & 44.76 & 40.39 & $47.77 *$ & $37.10 *$ & 42.42 & 42.01 & 5.09 \\
\hline Unsaturated (UFA) & 60.40 & 55.24 & 59.97 & $52.33 *$ & $62.90 *$ & 57.58 & 58.07 & 3.79 \\
\hline Monounsaturated (MUFA) & 39.98 & $36.19 *$ & 39.56 & $32.11 *$ & 41.63 & 42.43 & 38.65 & 5.73 \\
\hline Polyunsaturated (PUFA²) & $22.95 *$ & $19.04 *$ & $20.41 *$ & $20.22 *$ & $21.27 *$ & 15.15 & 19.84 & 3.39 \\
\hline UFA:SFA & 1.55 & 1.23 & 1.49 & 1.10 & $1.72^{*}$ & 1.36 & 1.41 & 10.03 \\
\hline PUFA:SFA & $0.61 *$ & 0.43 & $0.51 *$ & 0.42 & $0.57 *$ & 0.36 & 0.48 & 7.44 \\
\hline LNA:LA ${ }^{1}$ & $0.05 *$ & $0.07 *$ & $0.12^{*}$ & $0.20 *$ & $0.25 *$ & 0.03 & 0.12 & 3.79 \\
\hline$n-6: n-3^{1}$ & $19.03 *$ & $14.36 *$ & $8.63^{*}$ & $5.12^{*}$ & $4.03^{*}$ & 37.57 & 14.79 & 9.80 \\
\hline
\end{tabular}

*: Means significantly different from the control treatment, Dunnet's test at $5 \%$ probability. 1 - Linear effect at $1 \%$ de probability. 2 - Relative to LA and LNA. 


\section{Souza JG, Costa FGP, Queiroga RCRE, Silva JHV, Schuler ARP, Goulart CC}

\section{CONCLUSIONS}

Egg fatty acid profile was influenced by dietary linseed oil levels, resulting in eggs with higher PUFA (LA and LNA) content. Linseed oil was considered na excellent source of linolenic acid (18:3 w-3), favoring the incorporation of this acid in the egg yolk.

\section{REFERENCES}

Anton M, Nau F, Nys Y. Bioactive egg components and their potential uses. World's Poultry Science Journal 2006; 62:429-438.

Aymond WM, Van-Elswyk ME. Yolk thiobarbituric acid reactive substances and $n-3$ fatty acids in response to whole and ground flaxseed. Poultry Science 1995; 74:1388-1394.

Ahn DU, Sunwoo HH, Wolfe FH, Sim JS. Effects of dietary $\alpha$-linolenic acid and strain of hen on the fatty acid composition, storage stability, and flavor characteristics of chicken eggs. Poultry Science 1995; 74:1540-1547.

Baucells MD, Crespo N, Barroeta AC, López-Ferrer S, Grashorn MA. Incorporation of different polyunsaturated fatty acids into eggs. Poultry Science 2000; 79:51-59.

Calder PC. Immunoregulatory and anti-inflammatory effects of n-3 polyunsaturated fatty acids. Brazilian Journal of Medical and Biological Research 1998; 31:467-490.

Caston L, Leeson S. Research note: dietary flax and egg composition. Poultry Science 1990; 69:1617-1620.

Chen ZY, Ratnayake WMN, Cunnane SC. Oxidative stability of flaxseed lipids during baking. Journal of the American Oil Chemist's Society 1994; 71(6):629-632

Cherian G, Sim JS. Effect of feeding full fat flax and canola seeds to laying hens on the fatty acid composition of eggs, embryos, and newly hatched chicks. Poultry Science 1991; 70:917-922.

Cobos A, Hoz L, Cambero Ml, Ordónez JA. Dietary modification and hen strain dependence of egg yolk lipid. Food Research International 1995: 28:71-76.

Filardi RS, Junqueira OM, Laurentiz AC, Casartelli EM, Rodrigues RA, Araujo LF. Influence of different fat sources on the performance, egg quality, and lipid profile of egg yolks of commercial layers in the second laying cycle. Journal of Applied Poultry Research 2005; $14: 258-264$.

Folch J, Lees M, Sloane-Stanley GH. A simple method for the isolation and putification of total lipids from animal tissue. Journal of Biological Chemistry 1957; 226(1):497-509.

Gao YC, Charter EA. Nutritionally important fatty acids in hen egg yolks from different sources. Poultry Science 2000, 79:921-924.

Gómez MEDB. Modulação da composição de ácidos graxos poliinsaturados ômega 3 de ovos e tecidos de galinhas poedeiras, através da dieta. I. Estabilidade oxidativa [tese]. São Paulo (SP): Universidade de São Paulo; 2003.

Grobas S, Méndez J, Lázaro R, Blas C, Mateos GG. Influence of source and percentage of fat added to diet on performance and fatty acid composition of egg yolk of two strains of laying hens. Poultry Science 2001; 80:1171-1179.

Hartman L, Lago RC. Rapid preparation of fatty acid methyl esters. Laboratory Practice 1973; 494(22):475-476.

Leeson S, Caston L, Maclaurin T. Organoleptic evaluation of eggs produced by laying hens fed diets containing graded levels of flaxseed and vitamin E. Poultry Science 1998; 77(1):436-1.440.

Lewis NM, Seburg S, Flanagan NL. Enriched eggs as a source of n-3 polyunsaturated fatty acids for humans. Poultry Science 2000; 79:971-974

Li-Chan ECY, Powrie WD, Nakai S. The chemistry of eggs and egg products. In: Stadelman WJ, Cotterill OJ. Egg science and technology. $4^{\text {th }}$ ed. New York: Food Products Press; 1995. p.591.

Mandarino JMG. Características bioquímicas e nutricionais do óleo e do farelo de girassol. Londrina: Embrapa Centro Nacional de Pesquisa de Soja; 1992. 25 p.

Marshall AC, Sams AR, Van Elswyk ME. Oxidative stability and sensory quality of stored eggs from hens fed $1.5 \%$ menhaden oil. Journal of Food Science 1994; 59(3):561-563.

Mazalli MR, Faria DE, Salvador D, Ito DT. A comparison of the feeding value of different sources of fats for laying hens: 1. Performance characteristics. Journal of Applied Poultry Research 2004a; 13:274279 .

Mazalli MR, Faria DE, Salvador D, Ito DT. A comparison of the feeding value of different sources of fats for laying hens: 2 . Lipid, cholesterol and vitamin E profiles of egg yolk. Journal of Applied Poultry. Research 2004b; 13:280-290.

Meluzzi A, Sirri F, Manfreda G, Tallarico N, Franchini A. Effects of dietary vitamin $E$ on the quality of table eggs enriched with $n-3$ long-chain fatty acids. Poultry Science 2000; 79:539-545.

Milinsk MC, Murakami AE, Gomes STM, Matsushita M, Souza NE. Fatty acid profile of egg yolk lipids from hens fed diets rich in $n-3$ fatty acids. Food Chemistry 2003; 83:287-292

Rostagno HS, Albino LFT, Donzele JL, Gomes PC, Ferreira AS, Oliveira RF, Lopes DC. Composição de alimentos e exigências nutricionais de aves e suínos (Tabelas Brasileiras). Viçosa: Imprensa Universitária; 2005. $141 p$

Scheideler SE, Froning GW. The combined influence of dietary flaxseed variety, level, form and storage conditions on egg production and composition among vitamin E-supplemented hens. Poultry Science 1996; 75:1221-1226.

Sell JL, Choo SH, Kondra PA. Fatty acid composition of egg yolk and adipose tissue as influenced by dietary fat and strain of hen. Poultry Science 1968; 47:1296-1302. 
Shafey TM, Dingle JG, Mcdonald MW. Comparison between wheat, triticale, rye, soyabean oil and strain of laying bird on the production, and cholesterol and fatty acid contents of eggs. British Poultry Science 1992; 33(2):339-346.

Sim JS, Bragg DB, Hodgson GC. Effect of dietary animal tallow and vegetable oil on fatty acid composition of egg yolk, adipose tissue and liver of laying hens. Poultry Science 1973; 52:51-57.

Simopoulos AP. Symposium: role of poultry products in enriching the human diet with N-3 PUFA: human requirement for $\mathrm{N}-3$ polyunsaturated fatty acids. Poultry Science 2000; 79:961-970.

Stadelman WJ. The incredibly functional egg. Poultry Science 1999; 78:807-811.

Supercrac. Ração de custo mínimo. Versão 1.02 Windows. TD Software; 1993.

VanElswyk ME, Sams AR, Hargis PS. Composition, functionality and sensory evaluation of eggs from hens fed dietary Menhaden oil. Journal of Food Science 1992; 57(2):342-344.

VanElswyk ME. Comparison of n-3 fatty acid sources in laying hen rations for improvement of whole egg nutritional quality: a review. British Journal of Nutrition 1997; 78:S61-S69.

Watkins BA. Importance of essential fatty acids and their derivatives in poultry. Journal of Nutrition 1991; 121:1475-1485. 
